\section{1.はじめに}

皮虚科でみられる真菌性疾患の統計的観察は, 従来 大学病院における報告が多く, 農村におけるものは少 ない。そ乙で, 我々は養老中央病院皮膚科受診患者に ついて調査を行なった(困 1 )。

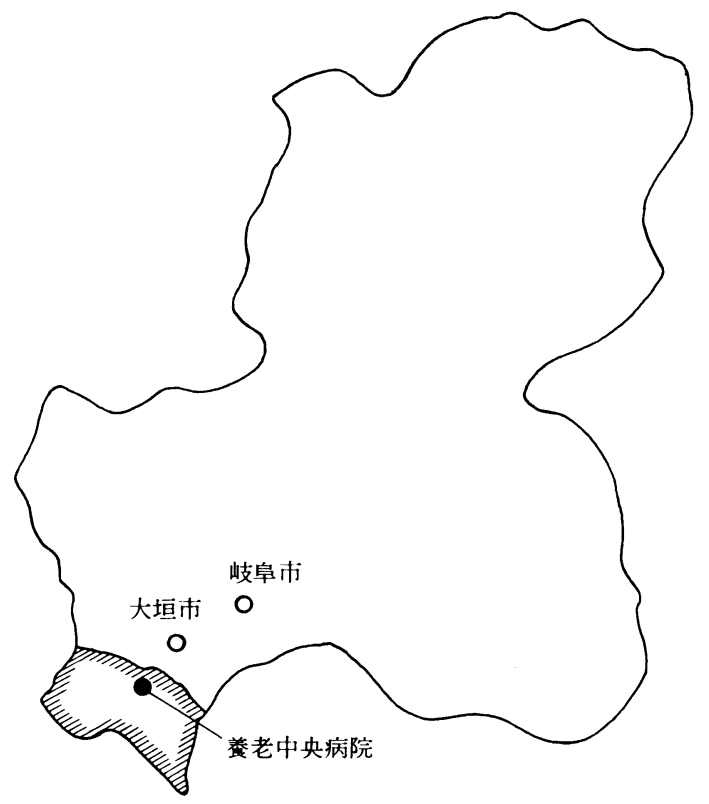

図 1.岐阜県全困および養老中央病院の 主なる診療圏

\section{2. 調查方 法}

養老中央病院皮膚科受診患者のうち, 真菌症を疑う 患者に対して, 病巣部より検体 (落屑, 爪および毛等) を採取し, $10 \% \mathrm{KOH}$ 滴下後, 鏡検並びにマイコセル 斜面培地に接種し培養 $\left(27^{\circ} \mathrm{C}\right)$ した。白癬の疑いのある コロニーに対しては, サブロー培地を用いて巨大培養

* 岐阜県厚生連 養老中央病院 (院長 : 大橋三与治博士) **岐皁大学医学部皮虚科教室

受付：昭和 51 年 6 月 7 日
並びにスライドカルチャーを, カンジダの疑いのある コロニーに対しては GS 培地で分離後, コーンミール 培地でスライドカルチャーを行ない同定した。

\section{3. 結果}

昭和 50 年度 1 年間の総患者数は 1,828 人で, そのう ち皮膚真菌症は 503 人 $(27.4 \%$, 男 228 人, 女 275 人) であった。白痒症患者は 380 人 (男 172 人, 女 208 人) で，総患者数の $20 \%$ であった。カンジダ症患者は 119 人 $(6.5 \%$, 男 48 人, 女 70 人), 癜風患者は 16 人 $(0.9 \%)$ であった。

病型および性, 年令別の患者数は, 表 1 に示したご とく, 白癬症では手および足の白癬が最も多く, 次い で体部白癬, 陰股部白癬, 爪白癬の順で, 頭部白癬亡 須毛部白癬が各 1 例ずつみられた。

2 病型以上の合併では, 手および足の白癬と爪白癬 の合併が最も多くみられた (表 2$) 。$

カンジダ症では, 乳児カンジダ症がほぼ半数を占め, 次いで間擦疹, 爪囲炎・爪炎, 指趾間びらん症が多か った。

月別の患者数は図 2 のでとく, 白癬症は $6 \sim 8$ 月に 多いが, 一方カンジダ症は $7 \sim 9$ 月に多い傾向がある ものの，ほぼ 1 年を通してみられた。

これらの白癬症患者についての鏡検および培養陽性 率は表 3 のでとくで，白癬症全体の鏡検陽性率は79\%， 培養陽性率は $67 \%$ であった。疾患別では, 陰股部白癬 および体部白癬は, 鏡検および培養陽性率ともに高く, 爪白癬では最も低い。

次に菌種別にみると, 白癬症については表 4 のでと く, 95\%がT.rubrumであった。T.mentagrophytes を検出した 3 例 (2 例は姉妹例) は，いずれも飼育して いるネコに脱毛斑をみたが, 菌の検出は失敗した。力 ンジダ症ではほとんどがC.albicans であった。

\section{4. 考按}

1）頻度

皮虑科外来患者数に対する白癬症の頻度は, 高橋は $6.8 \%$, 占部は $8.04 \%$, 三浦らは $4.5 \%$, 井上らは 7.2 
表 1. 病型, 性, 年令別 発症数

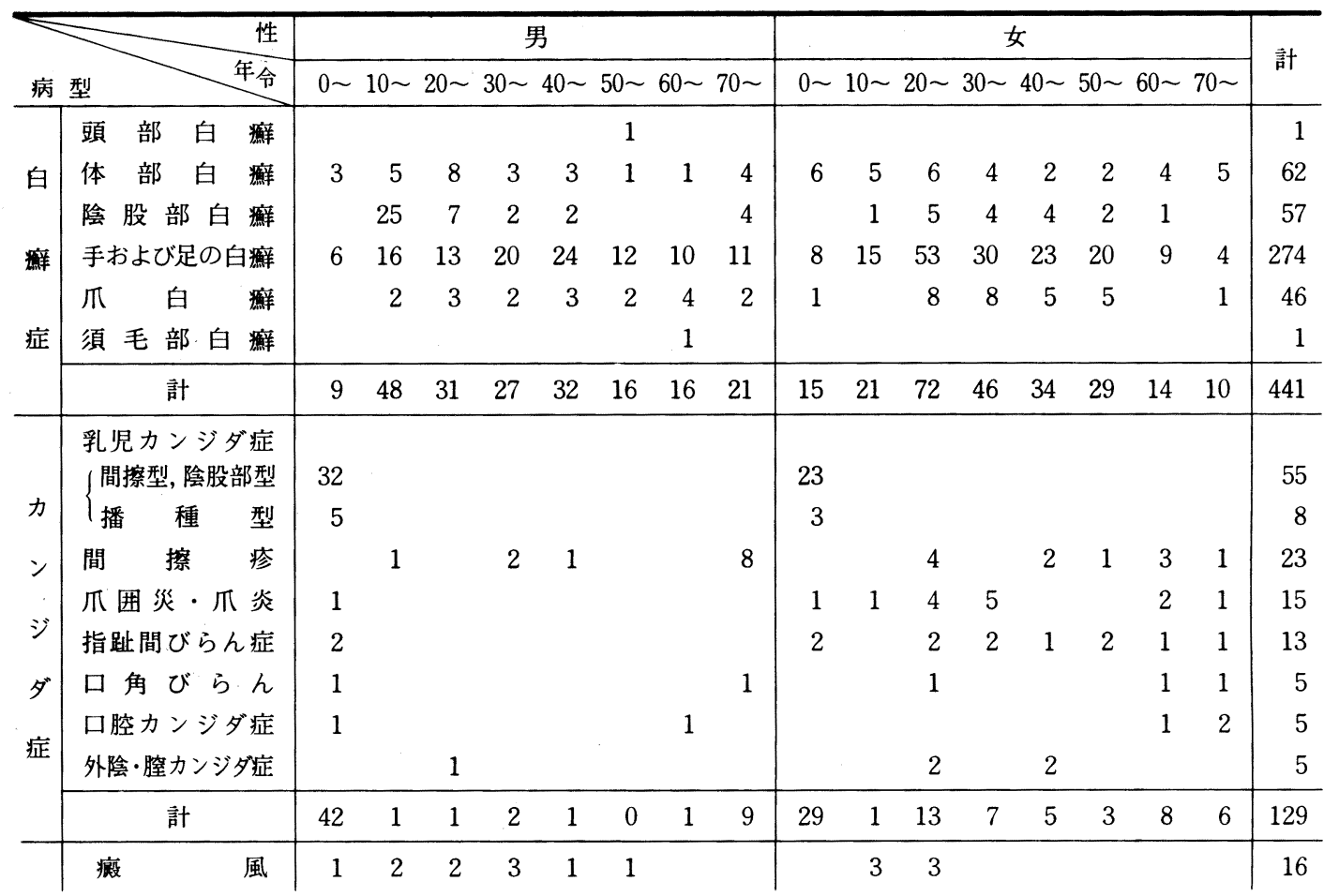

表 2. 病 型の合 併

\begin{tabular}{|c|c|c|}
\hline & 病 & 症例数 \\
\hline 症 & 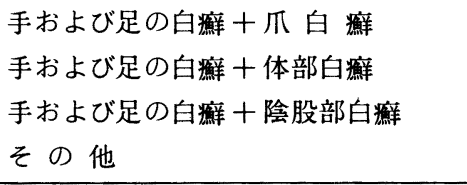 & $\begin{array}{r}38 \\
7 \\
6 \\
6\end{array}$ \\
\hline $\begin{array}{l}\text { カ ダ } \\
\text { シ症 } \\
\text { 多 }\end{array}$ & $\begin{array}{l}\text { 乳児カンジダ症十指趾間びらん症 } \\
\text { その他 }\end{array}$ & $\begin{array}{l}2 \\
7\end{array}$ \\
\hline & 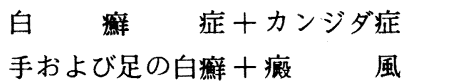 & $\begin{array}{l}6 \\
1\end{array}$ \\
\hline
\end{tabular}

\%であったと報告してお゙り，その頻度は $10 \%$ 以下で ある。

カンジダ症についてのそれは, 香川は, 昭和 31 年以 降 42 年までは大体 $0.1 \sim 0.3 \%$ 程度で, 43 年度は $0.6 \%$ に上昇したと述べている。原田らは $0.3 \sim 1.4 \%$ であっ たと報告しており，その頻度は $1 \%$ 前後である。

乙れに対し, 我々の病院における真菌症の頻度は, 白㿏症 20\%, カンジダ症 6.5\%であり, ともにかなり 高い率を占めている。前者が大学病院の外来における
図2.月別患 者 数

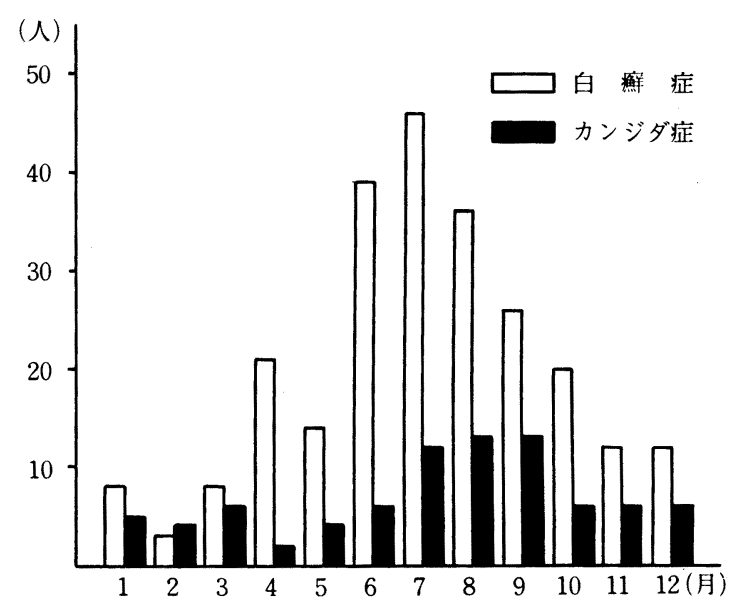

統計であり, 我々の病院とは対象となる患者層が異な っている。乙の乙とが頻度の違いとして現れたものと 考えたい。

しかし, 小野は, 昭和 47 年度の姫路赤十字病院皮 膚科の外来患者のうち, 真菌性疾患の頻度として $12.6 \%$ をあげているが, 我々の得た頻度はさらに高く, 農村 
表 3．白癬症の鏡検および培養陽性率

\begin{tabular}{|c|c|c|c|c|c|c|}
\hline 病 型 & 検鏡数 & $\begin{array}{l}\text { 検 鏡 } \\
\text { 陽 性 }\end{array}$ & 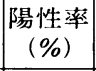 & 培養数 & $\begin{array}{l}\text { 培 香 } \\
\text { 陽 性 }\end{array}$ & \begin{tabular}{|c} 
陽性率 \\
$(\%)$
\end{tabular} \\
\hline 頭 部 白癖 & 1 & 1 & 100 & 1 & 1 & 100 \\
\hline 体 部 白 癬 & 58 & 53 & 91 & 47 & 40 & 85 \\
\hline 陰股部白癬 & 25 & 24 & 96 & 19 & 16 & 84 \\
\hline $\begin{array}{l}\text { 手および足 } \\
\text { の白群 }\end{array}$ & 108 & 78 & 72 & 89 & 48 & 54 \\
\hline 爪白癬 & 9 & 4 & 44 & 8 & 4 & 50 \\
\hline 須毛部白癬 & 1 & 0 & 0 & 1 & 1 & 100 \\
\hline 計 & 202 & 160 & 79 & 165 & 110 & 67 \\
\hline
\end{tabular}

表 4. 病型別検出菌種

\begin{tabular}{|c|c|c|c|}
\hline 病型 & T.rubrum & $\begin{array}{l}\text { T. menta- } \\
\text { grophytes }\end{array}$ & $\begin{array}{l}\text { その他 } \\
\text { (未同定) }\end{array}$ \\
\hline 頭 部 白 癬 & 1 & \multirow{6}{*}{3} & \multirow{6}{*}{2} \\
\hline 体 部 白 癬 & 37 & & \\
\hline 陰股部白癬 & 16 & & \\
\hline 手および足の白癖 & 46 & & \\
\hline 爪白癬 & 4 & & \\
\hline 須 毛部白癬 & 1 & & \\
\hline 計 & 105 & 3 & 2 \\
\hline
\end{tabular}

という地域性も関与しているかもしれない。

2) 月別患者数

白撚症については, 三浦らは, 北大では 7 月にピー クがあり, 他の 3 病院 (札帨病院, 札幌斗南病院, 滝川 病院)では8月にピークがあったと述べている。我々も 7 月にピークをみた。カンジダ症については, 富沢は 乳児寄生菌性紅斑について, 明らかに夏季に多いと述 ベている。我々もカンジダ症全体としては夏季に多く み, 境らの報告とほぼ一致する。

\section{3）白癬症の菌種}

三浦らは，昭和 42 年 9 月〜 43 年 8 月の 1 年間に, T.rubrum 219 株, T. mentagrophytes 192 株, その 他 50 株，高橋は同期間に T. rubrum 155 株, T.interdigitale 35 株および T.asteroides 1 株, その他 11 株, 松崎は, 同期間に国立別府病院では T.rubrum 74 株, T. mentagrophytes 13 株，その他 1 株，大分市の市川
は, T.rubrum 148 株, T. mentagrophytes 81 株, そ の他 6 株であったと述べている。井上らは昭和 43 年 〜 48 年の間に, T.rubrum 510 株, T.mentagrophytes 309 株，その他 38 株であったと報告している。

我々の調査では, T. rubrum 105 株に対し, T.mentagrophytes 3 株であり, T. rubrum の占める割合が 高かった。乙の乙とは, 本病院が地方病院であり, そ の対象となる通院患者は，おおよそこの養老地方に住 んでいる人に限られており, T. rubrum の検出が多い のは, ある程度乙の地方の真菌相をあらわしているも のと考えるが，乙の点に関して，さらに追求したい。

\section{5. 総括}

昭和 50 年度の養老中央病院皮膚科受診患者について 皮虑真菌症の調査を行なった。

1) 受診患者総数 1,828 人中, 白痽症は 380 人 (総患 者数の $20 \%)$, カンジダ症は 119 人 $(6.5 \%)$, 瘄風は 16 人 $(0.9 \%)$ であった。

2）皮䖉真菌症の患者は夏季に多い傾向がみられた。

3）白癖菌の菌種では, T.rubrum 105 株, T.mentagrophytes 3 株, その他 (未同定) 2 株が分離された。

稿を終るにのぞみ，御校閱頂きました東大皮虛科潼沢清宏講 師ならびに岐大皮有科森 俊二教授に深謝致します。

\section{文献}

1）高橋信也：東北大学皮虑科外来患者についてみた白㢈菌相， 真菌誌, $10,11 \sim 16$, 昭和 44.

2）占部治邦：九州地方における白㶍菌相，真菌誌，10，39 43, 昭和 44.

3）三浦祐唱他: 北海道地方, 特江机帨周辺における白淮菌相, 真菌誌, 10, 5 10, 昭和 44.

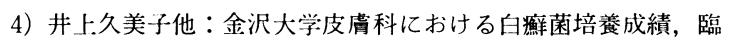
床皮虐，29，875～878，昭和 50 .

5）香川三郎：皮鹿科領域におけるカンジダ症，皮蔍臨床，12, $3 \sim 13$, 昭和 45 .

6）原田誠一, 植田時司：士波会誌，79，274 287, 昭和 44.

7）小野公義：統計からみた一地方病院の皮龙科の日常外来診療 について, 皮䖉臨床, 16, 1073 1076, 昭和 49.

8）富沢尊儀：最近異常に增加した乳児奇生菌性紅斑について, 皮庴臨床，15，292 302，昭和 48.

9）境繁雄：皮䖉カンジダ症一最近の傾向一, 臨床皮䖉，28, $733 \sim 740$, 昭和 49 .

10）松崎 統：大分地方の白編菌相, 真菌誌, $10,50 \sim 53$, 昭和 44 . 


\title{
Superficial mycotic infection at the dermatologic department of Yoro Central Hospital
}

\author{
Mihoko Tarao* and Makoto Yanagihara, M.D.**
}

\begin{abstract}
Statistical analyses on the superficial mycotic infection during one year (1975) were reported. 1828 patients visited our dermatologic department in the same period. The incidence of the superficial mycotic infection was $27.4 \%$ in total ; dermatophytosis of $20 \%$, candidiasis of $6.5 \%$, tinea vesicolor of $0.9 \%$.

In dermatophytosis, tinea pedis and manus were seen most commonly, followed by tinea corporis, tinea cruris, tinea unguium. Each tinea capitis and tinea barbae was seen only one case.
\end{abstract}

Tinea pedis and tinea unguium are the commonest combinations.

In candidiasis, candidiasis in infants occupy $50 \%$ of total candidiasis, followed by intertriginous candidiasis, paronychia and onychia and interdigitale candidiasis.

These superficial mycotic infection were seen in summer more than in other seasons.

T. rubrum were isolated mostly on culture (105 cases, $95 \%)$ and $\mathrm{T}$. mentagrophytes were only 3 cases $(2.7 \%)$.

* Yoro Central Hospital, Yoro, Gifu Pref, Japan

** Department of dermatology, Gifu University, School of Medicine (Director: Prof. Shunji Mori) Gifu, Japan . 